\title{
The Value of Alpha Forecasts in Portfolio Construction
}

\author{
Kingsley Fong ${ }^{\text {a }}$, David R. Gallagher ${ }^{\mathrm{a}}$, Adrian D. Lee ${ }^{\mathrm{a}, *}$ \\ Current Draft: $19^{\text {th }}$ May 2007 \\ ${ }^{a}$ Australian School of Business, The University of New South Wales, Sydney, N.S.W. 2052, \\ Australia
}

\begin{abstract}
This study examines a portfolio strategy which selects stocks using the undisclosed monthly holdings of Australian active fund managers. When considering a large range of strategies incorporating fund portfolio holdings information, the top performing strategies are robust to data-snooping and are both economically and statistically significant. These strategies are short term in nature, with significant performance lasting up to two months. However, when we account for look-ahead bias in the formation of a strategy, we document the absence of statistically significant performance. When we consider a strategy following the best performing strategy holding 20 stocks or more in the previous month, we find statistically significant alpha of at least 6.88 percent per year.

JEL classification: G11, G23
\end{abstract}

Keywords: Portfolio construction; Fund mimicking strategies

\footnotetext{
a Australian School of Business, The University of New South Wales, UNSW, Sydney, NSW 2052, Australia. This research was funded through an ARC Linkage Grant (LP0561160) involving Vanguard Investments Australia and SIRCA. The authors thank Tom Smith, Sue Wright and Garry Hobbes seminar participants at the Australian National University, the Investment Company Institute, Macquarie University and the University of Melbourne for helpful comments.
} 


\section{Introduction}

The managed funds industry has experienced unprecedented growth in the 1990's and 2000's. The investment advisory business, the primary domain of asset consulting institutions, has also rapidly expanded to now offer multi-manager (or fund-of-funds) investment vehicles, and these funds themselves are significantly large. Fund-of-funds are generally operated by a consulting intermediary directly selecting and managing a group of external fund managers.

In addition to fund-of-funds, a number of new investment products have been developed and operated internally. One such product offered by Russell Investment Group is a portfolio constructed based on fund holdings information of a group of fund managers, where the stocks most commonly held by the managers lead to the construction of a new portfolio that is managed internally by the intermediating consultant or multi-manager provider, or a so-called 'best ideas' fund. An example of this is a fund which holds stocks most commonly held overweight by active equity fund managers. These strategies have the advantage of providing investors with the benefit of more concentrated portfolios, and thus prospectively higher risk-adjusted returns. Indeed, the literature has shown that there is a significant (both economic and statistical) relationship between portfolio concentration and investment performance (see Kacperczyk, Sialm and Zheng (2005) and Brands, Brown and Gallagher (2005)).

Australia provides an interesting market to study such a 'best of ideas' fund for several reasons. First, a similar strategy is in use in the mutual funds industry and is relatively new (since 2006). Second, research shows Australian equity funds have higher stock picking ability in comparison to studies of U.S. equity funds. For example, Pinnuck (2003) finds a value-weighted alpha of about 1.94 percent per year in Australian active equity funds from 1990 to 1997. Third, the availability of monthly equity fund holdings, rather than quarterly holdings (as available in the US) allows for a less noisy test of the best ideas fund. The monthly frequency of equity 
holdings is also much closer in practice to the frequency of information at which a best of ideas fund would actually receive in order to incorporate the alpha forecasts within the fund. Indeed, Elton, Gruber and Blake (2007) show that using monthly rather than quarterly holdings improves the statistical power of predicting fund performance. Lastly, the absence of compulsory mutual fund holding disclosure in the Australian market may improve the persistence of alpha to be captured by the best of ideas fund as this lessens the chance of front-running.

Overall, the nature of the Australian market provides conditions for a best ideas fund to thrive. Also the availability of data allows us to estimate quantitatively the size of the alpha that such a fund may generate. Whether such strategies, utilizing alpha forecasts of other funds, are able to earn superior alpha is a matter of much contention. Theoretically, Holden and Subrahmanyam (1992) show that in a model where there are multiple privately informed agents strategically exploiting their information, all private information is revealed immediately and abnormal returns to all agents is zero. If however private information is not perfectly correlated across agents, Foster and Viswanathan (1996) show that abnormal profits can arise. This suggests that a strategy holding stocks common across multiple informed fund managers may earn abnormal profits. An example is a strategy of holding stocks both (informed) fund A and B are overweight in, where fund A uses a 'bottom up' philosophy and fund B uses macroeconomic forecasts (i.e. a 'top down' or thematic approach) to select stocks.

Empirically, Frank, Poterba, Shackelford and Shoven (2004) find that after fund expenses, hypothetical 'copycat' funds mimicking high expense funds (i.e. a proxy for informed or successful funds) earn statistically indistinguishable returns to the mimicked fund, despite the mimicking strategy having coarse data that may prevent positive return opportunities between quarterly disclosure dates. Wermers, Yao and Zhao (2006) find that a strategy of buying the stocks that successful managers hold in the immediate past period, and selling stocks of poor performing managers in the prior period, yields a return in excess of 7 percent per annum. This 
evidence suggests fund holdings, even at some lag, are valuable for ex-ante mimickers, and its value even accrues to free-riders when the information is made public.

Our study investigates how consensus alpha forecasts (i.e. the consensus ex-ante belief of a stock's future alpha by fund managers) might be derived from individual fund holdings to construct an alpha superior portfolio. Inferring alpha forecasts from portfolio holdings appears simple prima facie. However the alpha forecasts of a given fund may not be fully revealed in stock holdings due to factors such as index tracking, manager conservatism from job concerns (e.g., Chevalier and Ellison (1999)), and portfolio constraints given risk management requirements (e.g., Han and Wang (2004)). Fund managers may therefore hold stocks which do not necessarily indicate their alpha convictions. In an attempt to build precise alpha forecasts we turn to the literature on fund performance, herding and persistence in returns.

For the proposed best of ideas strategy to work, an implicit assumption is that fund research must have some value (i.e. they must be informed to a certain degree), and that valuable research undertaken by an investment institution can be inferred from its fund holdings. Indeed, recent studies find that active funds earn statistically significant and positive risk-adjusted returns on a gross basis (see for example Daniel, Grinblatt, Titman and Wermers (1997) and Wermers (2000)); however this is offset by management expenses. In Australia, Fong, Gallagher and Lee (2007), Chen, Comerton-Forde, Gallagher and Walter (2005), and Pinnuck (2003) also find that active funds display some evidence of stock picking skill.

Evidence of manager skill appears to be stronger in literature where researchers have examined portfolio holdings and trading data, supporting the notion that alpha is more easily detected from individual stock holdings information (e.g., Elton, Gruber and Blake (2007)). Chen, Jegadeesh and Wermers (2000) find that buy trades statistically outperform sell trades of portfolio managers in the subsequent period. Pinnuck (2003) finds similar results for the 
Australian market. Funds with more concentrated ${ }^{1}$ holdings have also been found to generate higher risk-adjusted returns. Kacperczyk, Sialm and Zheng (2005) find that funds with concentrated holdings in particular industries perform better than funds with more diverse holdings. Similarly, Wermers (2003) and Brands, Brown and Gallagher (2005) find a positive relationship between fund concentration and performance in U.S. and Australian funds respectively. Nanda, Wang and Zheng (2004) document that fund families offering funds with a wide variety of investment strategies significantly underperform low variation fund families. Daniel et al. (1997) and Chen, Jegadeesh and Wermers (2000) find that aggressive growth funds outperform growth and value funds consistent to funds which take larger stock bets tending to also to have greater risk-adjusted performance. These findings suggest that stocks held overweight by funds exhibit higher alpha forecasts.

Fund herding is another source in improving the precision in consensus alpha forecast estimates. Wermers (1999) finds stocks that herding funds buy outperform stocks that herding funds sell in the following six months. Similarly, Han and Wang (2004) find stocks with higher institutional ownership outperform stocks with lower institutional ownership. Fong, Gallagher, Gardner and Swan (2007) examine a series of fund trades mimicking an initially disguised trade, and find subsequent profitability for mimickers up to the sixth institution, and which does not reverse for the leader in the next twelve months. Similarly, Sias, Starks and Titman (2006) find a positive correlation between changes in institutional ownership and stock returns of which permanent price impacts are associated with information effects. Common ownership in a stock thus appears to represent a credible and exploitable signal of a consensus stock alpha forecast.

Another factor that might be used as a mechanism for improving alpha forecasts is with respect to the past performance of funds. However, literature on fund persistence is mixed.

\footnotetext{
${ }^{1}$ That is in terms of the number of stocks held and portfolio weights in stocks above the market index.
} 
Carhart (1997) finds persistence only exists for poorly performing funds after controlling for momentum. In a more recent study, Bollen and Busse (2005) use shorter quarterly ranking and evaluation periods than Carhart (1997) and find short-term performance persistence. They find however when considering a strategy of chasing past fund performance, the return is not economically significant after fees and taxes. In light of this, we attempt to better capture the alpha forecasts of past winners through inferring forecasts from individual portfolio holdings, and our analysis is without reference to aggregate fund fees.

Our study focuses on three important portfolio construction measures in an attempt to create an alpha superior portfolio: average overweight positions, fund popularity, and the fund alpha persistence in a stock (as developed by Wermers, Yao and Zhao (2006)). We use monthly stock holdings of Australian active equity funds from January 1997 to December 2001. The Australian market presents a unique and important setting to test the value of holdings information, as portfolio disclosure is voluntary, unlike in the U.S. where holdings must be disclosed quarterly. ${ }^{2}$ As such, our study is the first to quantify the value of private information contained in the portfolio holdings of active equity managers, and within an environment where front running opportunities should be less apparent.

\section{Data}

We use month-end portfolio holdings from the Portfolio Analytics Database (PAD). The database comprises the holdings of 38 active Australian fund managers ${ }^{3}$ as well as their self declared investment objectives or styles ${ }^{4}$. This sample is representative of the size and styles of

\footnotetext{
${ }^{2}$ The SEC requires that mutual funds disclose their holdings quarterly, and at a lag of no greater than 60 days from the fiscal quarter-end.

${ }^{3}$ One fund is removed as it is simply a duplicate of another fund in the same fund family.

${ }^{4}$ Defined as GARP (Growth at a Reasonable Price), Growth, Style-Neutral and Value
} 
Australian equity mutual funds. Gallagher and Looi (2006) provide a detailed description of the database. Monthly dilution-adjusted share returns, month-end market capitalization and stock ASX industry classification data are sourced from the Centre for Research in Finance (CRIF) Share Price and Price Relative (SPPR) database. Daily stock prices and monthly returns of the ASX/S\&P 300 Accumulation Index are sourced from the Securities Industry Research Centre of Asia-Pacific (SIRCA). The Aspect Financial database is used for financial year end book value (Aspect item ID 7010). Month-end weight compositions of the S\&P/ASX 300 are sourced from Vanguard Investments Australia.

Table 1 Panel A provides a fund count at each December year-end by different styles and whether the fund belonged to the top 15 largest equity managers or it was a boutique fund. Over our sample period, the number of funds nearly doubles from 19 funds in 1997 to 37 funds in 2001. Throughout the years we see a doubling in the number of GARP, Style Neutral and Value funds with the number of Growth funds remaining static.

Figure I shows the cumulative overweight position from the largest to smallest market capitalization stocks relative to the S\&P/ASX 300 for GARP (Panel A), Growth (Panel B), Style Neutral (Panel C) and Value (Panel D) funds. The overweighting composition varies widely across styles. GARP funds overweight stocks from the largest 10th to 25 th percentile of stocks, Growth from the 2nd to 19 th, Style Neutral from the 1st to 10th percentile and Value for the 10th to 30 th percentile. Weightings in small capitalization stocks (50th percentile and beyond) are generally underweight or market neutral for all styles. With the exception of Value funds, funds are either overweight or market neutral in the top 10 percentile (largest 30 stocks by market capitalization) suggesting these stocks are held for index tracking purposes.

Table 1 Panel B looks at the average number of stocks held in common between styles at each month-end, with the diagonal of results representing the average number of stocks held in a particular style. GARP funds hold the most number of stocks on average at 151 . This may be due 
to more GARP funds existing with diverse strategies within this style. Value funds hold 59 of 77 stocks in common with Growth funds indicating a great degree of similarity between Growth and Value fund stock holdings despite the opposing strategies. Overall, all styles hold at least 70 percent of stocks in common with Growth funds.

\section{Methodology}

\section{Performance Benchmarks}

We use two characteristic-based benchmarks to calculate the alpha or risk-adjusted return of a stock: the index-adjusted benchmark methodology of Fong, Gallagher and Lee (2007) and for robustness in unreported results, the characteristic-based benchmark following Pinnuck (2003).

The index-adjusted benchmark portfolio formation methodology bears similarities to that of Daniel et al. (1997) and Pinnuck (2003) with the exception of using index weights to benchmark portfolios to ensure zero alpha for an index portfolio. A stock enters a characteristic benchmark portfolio in a given month $t$ if it meets the following data criteria: Market capitalization and share price data for month $t-1$ (from the CRIF SPPR), book value data in the previous year (ASPECT item ID 7010) or if the stock's current year's reporting date is 3 months or more earlier than month $t-1$, the current year's book value ${ }^{5}$, monthly returns in the past 13 months and have a market weight in the S\&P/ASX 300 for month $t-1$.

The S\&P/ASX 300 universe is used as the reference index rather than the entire ASX share universe in recognition of the skewed distribution of market capitalization to the largest

\footnotetext{
${ }^{5}$ Under Australian Stock Exchange (ASX) periodic disclosure rules during our sample period, an entity must disclose its accounts no later than 75 days after the end of its accounting period.
} 
stocks in the Australian market as documented by Fong, Gallagher and Lee (2007). Stocks beyond the largest 300 do not represent the tradable universe for fund managers.

The benchmark portfolios are formed as follows. At the end of each month, all stocks which meet our data criteria are placed into three portfolios ranked upon its month-end market capitalization. Within each of these three portfolios, the stocks are then further sorted into three portfolios by its current/prior year book-to-market. The book-to-market measure is the prior year book value over the month-end market capitalization.

Finally, each market capitalization/book-to-market portfolio is sorted into three portfolios by its past twelve month returns with one month skip to prevent bid-ask bounce. 27 characteristic-based portfolios with approximately ten stocks in each are formed from this triple sort procedure.

Each portfolio of stocks is then monthly value-weighted and re-weighted according to the S\&P/ASX 300 weightings and held for six months to form the monthly characteristic benchmark returns. Thus a stock's matching characteristic benchmark portfolio for a given month is the equal-weighted return of six overlapping benchmark portfolios.

\section{Fund Performance}

We measure the alpha of a fund or portfolio of stocks as the value-weighted average of individual stock returns less its respective characteristic benchmark return:

$$
C S_{t}=\sum_{i=1}^{N} w_{i, t-1}\left(R_{i, t}-R_{t}^{b i, t-1}\right)
$$

Where $w_{i, t-1}$ is the weight of stock $i$ in month $t-1$

$R_{i, t}$ is the monthly return of stock $i$ in month $t$

$R_{t}^{b i, t-1}$ is the monthly return of the matching characteristic-benchmark portfolio to stock $i$ at month $t-1$ in month $t$. 


\section{Overweight Measure Conditional on Fund Persistence}

Following Wermers, Yao and Zhao (2006), we use the weighted average alpha to measure the weight of funds in a stock. This measure assumes skill persistence in funds and as such stocks in which past high performing funds currently hold are given higher alpha forecasts and vice versa. This estimate of stock $i$ 's alpha forecast (AlphaF) at time $t$ for fund $j$ is given by:

$$
\alpha_{i t}^{S}=\frac{\sum_{j=1}^{M} w_{i j t-1}{ }^{f}{ }_{j t-1}}{\sum_{j=1}^{M} w_{i j t-1}}
$$

Where, $w_{i j t-1}$ is the weight in stock $i$, at time $t-1$ for fund $j$

$$
\alpha_{j t-1} \text { is the realized past 12-month alpha of fund } j \text { at time } t-1
$$

As such, if past high performing funds currently have large positive weights in stock $i$, this

increases the value of the alpha forecast measure, $\alpha_{i t}^{S}$. Conversely if past poor performing funds hold stock $i$, this will reduce the measure. We use characteristic-selectivity returns following Fong, Gallagher and Lee (2007) (see equation 1) to calculate a fund's past twelve-month alpha.

\section{Unconditional Measures of Overweight}

To measure how overweight a manager is in a stock we calculate the difference of the fund manager's weight to the S\&P/ASX 300 index weight for month $t$, Oweight:

$$
\text { Oweight }_{i, t}=w_{i, t}-w_{i, m t}
$$

Where $w_{i, b t}$ is the fund weight in stock $i, w_{i, m t}$ is the index weight of stock $i$. An equalweighted average Oweight measure across funds in a stock is used. One problem with this measure is that by virtue of a fund holding fewer stocks, this measure will be larger than for a more diversified fund. Thus basing our stock selection strategy on this measure would tend to 
favor stocks held by concentrated funds. For robustness, we also use the weight multiple over the index, Indextimes:

$$
\text { Indextimes }_{i, t}=\frac{w_{i, t}}{w_{i, m t}}
$$

Similarly, we calculate the equal-weighted average Indextimes of a stock for all funds holding the stock. OweightA and IndextimesA are also used for robustness, which are median (rather than equally-weighted) versions of the above.

\section{Fund Popularity}

As a measure of herding and consensus high alpha forecasts, the popularity of a stock is measured by a simple count of the number of funds holding stock $i$ in a given month.

Formally:

$$
\operatorname{Pop}_{i, t}=\sum_{j=1}^{M} \frac{\left(w_{j, i t} \mid w_{j, i t}>0\right)}{w_{j, i t}}
$$

\section{Descriptive Statistics}

Returns of Stocks Held and Not Held by Managers in the PAD Database

To see whether simply knowing what stocks are held by all funds is a viable strategy, we conduct the following naïve strategy. Every month from 1997 to 2001 we divide stocks in the S\&P/ASX 300 into those held by at least one fund manager and those not held at all. We form value-weighted portfolios out of these two groups of stocks and calculate each portfolio's riskadjusted return (using characteristic-based benchmark returns) and raw return in the next month. Table 2 Panel A reports the average returns for held ('Held') and not held ('Not Held') stocks by PAD fund managers and for comparative purposes, value-weighted portfolio of all PAD fund 
equity holdings and ('VW PAD Funds'). The near zero alpha of 0.12 percent per year of Held indicates simply holding stocks funds hold does not aid in stock selection. Interestingly, the large and 1 percent statistically significant negative alpha and raw return of Not Held indicates an ability of funds to avoid poor-performing stocks.

Table 2 Panel B reports by style groups the risk-adjusted returns, average number of stocks held, number of stocks held by and also the total index weight of stocks to the S\&P/ASX 300 this represents. Overall, of the 266 stocks in the S\&P/ASX 300, 208 or 78 percent are held by at least one fund manager representing 97.58 percent of index weight. This indicates an avoidance of small stocks by all funds. Despite this large holding of stocks, individual funds hold on average 48 stocks and this is consistent throughout styles with Top 15 funds tending to hold more stocks (61 stocks) and boutique funds less (41 stocks).

GARP and 'Middle' (funds not classified as either Top 15 or Boutique) are the poorest performers over the sample period while Style Neutral and Value funds performed the best, both with risk-adjusted returns of 2.11 percent per year (1 percent and 10 percent statistically significant respectively).

\section{Fund Persistence}

This section tests for persistence in the PAD database. While the literature on fund persistence is extensive in the U.S., the persistence of Australian funds in the PAD database has not been investigated. Every month from January 1997 to December 2001, funds with adequate past return series are ranked by their past alpha (measured using characteristic-based based returns following Fong, Gallagher and Lee (2007)) into three groups - high, mid and low past alpha. Table 3 reports each group's equal-weighted average monthly alpha for $\mathrm{Q}+1$ to $\mathrm{Q}+4$ quarters. Panel A reports using past month alpha groups, Panel B using the past-quarter alpha and Panel C using the past-year alpha. Consistent with Bollen and Busse (2005), we find evidence of 
short term persistence for past high ranking funds for at least one quarter. High ranking funds have statistically significant alpha at the 1 percent level for $\mathrm{Q}+1$ to $\mathrm{Q}+2$ quarters and for a year $(\mathrm{Q}+1$ to $\mathrm{Q}+4)$ regardless of the method of ranking past alpha performance. Past high performing funds also statistically significantly outperform low performing funds in $Q+1$ as evident in the 'High - Low' row, regardless of ranking method. This suggests skill is persistent at least in the short term for past high performers. However beyond one quarter the alpha of high past performers is not statistically different to past poor performers.

\section{Results}

\section{Alpha Forecast Portfolios}

In this section we create portfolios in the spirit attempting to mimic a 'best ideas' stock picking strategy. In later sections we consider alternative specifications. We use our overweight measures (Indextimes, IndextimesA, Oweight, OweightA and AlphaF) and Pop as our stock screening measures. Our methodology is as follows: at the end of every month, stocks with at least two managers holding it are given a percentile ranking based on Pop and an overweight measure. For example a score for a stock is formed by 30 percent of the percentile rank for Indextimes plus 70 percent of the percentile rank for Pop. 20 stocks with the highest score are then placed into equal-weighted portfolios. The portfolios are rebalanced monthly and held for

one month. In recognition that past fund information may not be instantaneously available, the portfolio is held in the second rather than the first month after portfolio formation ("1-month skip'). A note should be made that we report conventional portfolio t-stats which assumes the independence of tests. In the following section we adjust for this bias. 
Table 4 reports our results using average monthly annualized alphas ${ }^{6}$. While the majority of strategies earn positive alpha, only a handful are statistically significant. Of those which are statistically significant, the alphas are larger than that of the 1.27 percent per year for the valueweighted PAD sample in Table 2. For example, a strategy of buying the top 20 stocks by 10 percent in Pop and 90 percent factor in overweight measure yields an alpha of 3.95 percent per year, statistically significant at the one percent level. Conversely, no strategy of holding stocks with 100 percent weighting solely on an overweight measure yields statistically significant alphas. Using Oweight and Indextimes portfolios and their variants, OweightA and IndextimesA, have relatively weak ability to earn alpha. Of these strategies, IndextimesA has the most number of successful strategies with four out of the nine mixed strategies with positive alpha statistically significant at the 10 percent level.

Strategies using a mix of AlphaF and Pop to screen stocks appear to be most successful with six out of the nine strategies with at least ten percent statistical significance. A strategy of factoring 40 percent in AlphaF and 60 percent in Pop earns the highest alpha of 6.38 percent per year. Strategies using 30/70, 50/50 and 60/40 strategies also yield statistically significant alphas.

\section{Tests for Data-snooping}

While the above results may suggest strategies incorporating fund holdings are successful and earn very high alphas, there is the possibility our findings are subject to data-snooping (or data-mining). As such, the reported t-stats in Table 4 may be biased upwards as we do not take into account of the repeated sampling of the same data. Data-snooping bias would still pervade the results even if all the strategies we tested were statistically significant as we may have by luck, or lack of knowledge, missed a wide range of unsuccessful strategies. As such, in this

\footnotetext{
${ }^{6}$ Using the characteristic-based benchmarks of Pinnuck (2003) does not change the implications of our results.
} 
section we control for data-snooping using White's Reality Check Test (RCT) following White (2000). Sullivan, Timmermann and White (1999) also use this test to adjust for data-snooping on the performance of technical trading strategies. Appendix I details the RCT methodology we use.

In an attempt to replicate the universe of possible strategies, we extend the methodology used in Table 4. Every month from 1997 to 2001, stocks with at least two managers holding it are given a percentile ranking based on Indextimes, IndextimesA, AlphaF or Pop. A score is created by weighting two of the measures. The combinations are the same as the ones used in the Table 4. In addition, we also include combinations of Indextimes, IndextimesA, Oweight, and OweightA with AlphaF as the second weighting factor. We use weighting increments of 5 percent (e.g. 5 percent in the first measure, 95 percent in the second, 10 percent/90 percent, ... etc.). The top $10,15,20,25$ or 30 stocks with the highest scores are then placed into equal-weight (EW), popularity-weight (PW) or value-weight (VW) portfolios. Where $\mathrm{PW}$ is the equally weighted average fund weight in a stock normalized by the sum of average fund weights in the portfolio. The portfolio is held in the second month following formation for one month (i.e. the first month is skipped) and rebalanced monthly. This results in a universe of 2655 strategies.

Table 5 presents annualized average alpha and information ratio (IR) ${ }^{7}$ of the top five strategies with conventional t-stat and White's RCT P values. Nstocks is the number of stocks held for the strategy, 'Cap Rank' is the equally-weighted average quintile by market capitalization $(1=$ smallest quintile, $5=$ largest quintile $)$ of stocks in the portfolio. Panel A reports the top five strategies by highest IR and Panel B by highest alpha for the entire universe of strategies. Panel C reports the top five strategies by highest IR and Panel D by highest alpha restricting the universe to strategies holding 20 or more stocks (resulting in 1593 strategies). This

\footnotetext{
${ }^{7}$ Measured as the annualized alpha in month $t$ over the annualized average daily standard deviation of the portfolio's return in month $t$.
} 
restriction is out of practicality as there are much greater transaction costs and price impact impediments for a fund in holding less than 20 stocks.

The majority of top performing strategies have a Cap Rank of 3 or above suggesting the average strategy holds mid cap stocks. However since all strategies are value-weight except one, the strategies would bias towards large capitalization stocks. The results show that after controlling for data-snooping, only a few strategies have statistically significant alpha and IR. None of the strategies we report in Table 4 are RCT statistically significant suggesting these results are statistically weak after adjusting for data-snooping. Looking at Panel A and Panel B, while all strategies have statistically significant IR after adjusting for data-snooping, only two strategies, 85 percent AlphaF/15 percent Pop and 90 percent AlphaF/10 percent Pop have statistically significant alpha. In Panel $\mathrm{C}$ and Panel $\mathrm{D}$, where the universe is restricted to strategies holding 20 stocks or more, two strategies ${ }^{8}$ show statistically significant alpha at the 10 percent level. The weaker statistical significance suggests these strategies are however subject to data-snooping bias.

\section{Sub Period Portfolio Performance for One to Six Months}

This section tests the longevity and addresses out-of-sample issues of the strategies found to be White's RCT statistically significant in Table 5. As our sample period is too small to conduct out-of-sample testing, we divide our sample into two periods, January 1997 to June 1999 and July 1999 to December 2001, to test the robustness of the strategies. We also measure the alpha and information ratio for the first to sixth month $(\mathrm{T}+1$ to $\mathrm{T}+6)$ from the start of holding the portfolio.

\footnotetext{
${ }^{8} 60$ percent Indextimes $A$ and 40 percent Pop value-weighted and holding 20 stocks and 90 percent $A l p h a F / 10$ percent Pop value-weighted and holding 20 stocks.
} 
Table 6 reports average monthly alpha and information ratios for the top four strategies with conventional t-statistic significance. The measures for the entire sample period (January 1997 to December 2001) for $\mathrm{T}+1$ is reported for completeness and is the same as those reported in Table 5. While all four strategies are positive in each sub period for $\mathrm{T}+1$ and $\mathrm{T}+2$ periods, only two strategies (85 percent AlphaF 10 stocks, and 40 percent IndextimesA 20 stocks) show statistical significance in $\mathrm{T}+1$ and only in the latter half of the sample. The two 10 stock strategies also show statistically significant measures in $\mathrm{T}+2$, though only when the entire sample period is considered. The results suggest, with our limited data points, performance is skewed to the latter half of the sample for the strategies and also that abnormal returns of the strategies are short-lived. This is consistent with the short term nature of the uncorrelated private information the strategies attempts to capture.

\section{Alpha Forecast Portfolios Based on Best Past Performing Strategies}

This section investigates strategies using the best past performing strategy to avoid lookahead bias. As a fund manager only knows in hindsight the best past performing portfolio strategy, the strategies found in Table 5 may not be known when forming a portfolio. To address this issue, we test a strategy similar to the cumulative wealth (CW) strategy used by Sullivan, Timmermann and White (1999) in forming a portfolio based on the best past performing strategy to date.

Every month from 1997 to 2001, the best performing portfolio strategy to date from the universe described in Table 5 based on the highest past cumulative alpha (or average information ratio) is used to form a portfolio that is held on the following month after formation (one month skip). As we lack the extensive 100 year period Sullivan, Timmermann and White (1999) use, we also use rules selecting the strategy with the highest past month, quarter or year alpha (or 
information ratio) for robustness. Sullivan, Timmermann and White (1999) note since the CW strategy relies on historical data, no adjustment for data-snooping bias is necessary.

Table 7 reports results for the cumulative wealth strategy using the entire universe of portfolio strategies in Panel A and for 20 stock plus strategies in Panel B. The CW strategies are not statistically significant and in the case of using only 20 stock plus strategies, has an alpha of 1.95 percent per year (t-stat -0.49$)$. This suggests the best performing past strategy to date has little predictive ability. In Panel B where we consider the more practical 20 stock plus strategies, strategies using the best past month alpha, past quarter alpha and past month IR strategies are statistically significant and positive for both alpha and IR. A strategy of following the best past month strategy with the highest IR holding 20 stocks or more earns 6.99 percent alpha (t-stat 2.84) and has an information ratio of 0.61 ( $t$-stat 2.25). In unreported results, similar significance is found when using strategies considering only the best past performing 20 stock strategy, and weaker significance for 25 stock and 30 stock only strategies. This suggests the best performing higher stock strategies provide show some predictive ability when considering near term past performance.

The fact that only past information strategies considering immediate past information earn abnormal returns raises the question of whether a fund manager would have recognized such an opportunity. Firstly, the strategies we identify rely on strategies holding 20 stocks or more which a fund could practically undertake. Secondly, due to the short time series, our CW strategies only captures the best strategy to date arbitrarily starting from January 1997 compared with the 100 year period Sullivan, Timmerman and White (1999) use. As such this may not be a reliable reflection of the best historically performing strategy. Third, the nature of the strategies of capturing short term private information would purport that a strategy of using past historical returns should only consider information in the immediate past. As such it may be possible for a fund manager to recognize and follow a strategy with the best past alpha or IR. 


\section{Conclusion}

This study examines the value of alpha forecasts in portfolio construction, with reference to the monthly portfolio holdings information of active equity fund managers. We examine how ex-post portfolio holdings of active managers in Australia may be used to construct a portfolio aimed at outperforming both the market and the peer group of managers. Our findings are not resoundingly in favor of such strategies when we consider issues of data-snooping, look-ahead bias, sub-period sampling, and portfolio performance longevity.

When considering a large range of strategies using fund holdings information, the top performing strategies are robust to data-snooping, and are also economically significant. The significant performance of these strategies lasts for, at most, two months following portfolio formation and appears to primarily arise in the latter half of the sample period. As a consideration for look-ahead bias, when we consider a strategy of using the past period best performing strategy to date to form a portfolio, alpha and information ratio are not statistically significant. However, when we consider the best performing strategy holding 20 stocks or more in the immediate past, we find economically and statistically significant alpha and information ratio. This suggests the strategies we consider that use fund holdings information have little predictive ability, except when considering the immediate past.

Our study is subject to a number of caveats. Our limited times series of fund holdings data of 60 months means that we are constrained statistically, especially when considering sub periods. Also, while we have made efforts to make the strategies practical, such as in skipping one month following formation, the strategies are mechanical and naïve in nature. As such, much refinement could be made to consider more sophisticated strategies such as the use of daily transaction data. However even if higher (conventional) statistically significant performance 
measures are achieved, similar rigorous testing of such strategies as the ones covered in our study are required to ensure the results are not subject to bias.

\section{Appendix I. White's Reality Check Test}

This section details the White's 'Reality Check Test' (RCT) methodology as developed in White (2000) and used to control for data-snooping bias in Section V Our sample period consists of 60 months from January 1997 to December 2001. Our methodology (and notation) largely follows that of Sullivan, Timmermann and White (1999), using the stationary bootstrap methodology of Politis and Romano (1994). The universe of $l$ strategies is indexed by $k$. We use two performance measures, alpha, as measured by the characteristic-selectivity measure Fong, Gallagher and Lee (2007) develop, and the information ratio which is the annualized monthly alpha over the annualized average daily standard deviation of the portfolio's return. The methodology is as follows:

1. Uniform randomly choose $p$ from 0 to 1 .

2. Randomly draw $l$ from a geometric distribution for a uniform randomly chosen $x$, where:

$$
l(x)=\left\{\begin{array}{cc}
(1-p)^{x-1} p & 0<p<1, x=1,2,3, \ldots \\
1 & p=1, x=1
\end{array}\right.
$$

3. For each portfolio strategy $k$ 's time series of returns, select a consecutive time series sample of $l$ length, with the same random starting point for each strategy.

4. Place the selected series of returns from step 3 at the end of bootstrap $i$, for each portfolio strategy $k$, to form a new bootstrap time series. Where $i$ indexes bootstrap iterations.

5. Repeat steps 2 to 4 until a new bootstrap sample of 60 periods (i.e. the same length as the original sample period) is formed for each portfolio strategy $k$. 
6. Calculate the average monthly alpha (or IR) for bootstrap sample $i$ for each strategy $k$, to form $\bar{\alpha}_{k, i}^{*}$ (or $I \bar{R}_{k, i}^{*}$ ) where $\mathrm{i}=1, \ldots, \mathrm{B}$.

7. Reset the bootstrap sample.

8. Repeat steps 2 to 7500 times to form $\mathrm{B}=500 \alpha_{i}^{*}$ (or $I R_{i}^{*}$ ) bootstrap values.

9. Using the $500 \alpha_{i}^{*}\left(I R_{i}^{*}\right)$ measures, create the bootstrap distribution. Where:

$$
\begin{gathered}
\overline{V_{l}}=\max _{k=1, \ldots, l}\left\{\sqrt{n}\left(\bar{\alpha}_{k}\right)\right\} \\
\bar{V}_{l, i}^{*}=\max _{k=1, \ldots, l}\left\{\sqrt{n}\left(\bar{\alpha}_{k, i}^{*}-\bar{\alpha}_{k}\right)\right\}
\end{gathered}
$$

Where $\bar{\alpha}_{k}$ is the realized alpha (IR) measure for strategy $k$.

Compare $\bar{V}_{l}$ to the quantiles of $\bar{V}_{l, i}^{*}$ to calculate White's RCT.

\section{References}

Bollen, N.P. B. and J.A. Busse, 2005, Short-term persistence in mutual fund performance, Review of Financial Studies 18, 569-597.

Brands, S., S.J. Brown and D.R. Gallagher, 2005, Portfolio concentration and investment manager performance, International Review of Finance 5, 149-174.

Carhart, M. M., 1997, On persistence in mutual fund performance, Journal of Finance 52, 57-82.

Chen, C., C. Comerton-Forde, D.R Gallagher and T.S. Walter, 2005, Investment manager skill in small-cap equities, Working paper, University of New South Wales.

Chen, H.L., N. Jegadeesh and R. Wermers, 2000, The value of active mutual fund management: An examination of the stockholdings and trades of fund managers, Journal of Financial and Quantitative Analysis 35, 343-368.

Chevalier, J. and G. Ellison, 1999, Career concerns of mutual fund managers, Quarterly Journal of Economics 114, 389-432. 
Chopra, N., J. Lakonishok and J. R. Ritter, 1992, Measuring abnormal performance: Do stocks overreact?, Journal of Financial Economics 31, 235-268.

Daniel, Kent, Mark Grinblatt, Sheridan Titman and Russ Wermers, 1997, Measuring mutual fund performance with characteristic-based benchmarks, Journal of Finance 52, 1035-1058.

Elton, E. J., M. J. Gruber and C. R. Blake, 2007, Monthly holding data and the selection of superior mutual funds, Working paper, New York University.

Fong, K., D. R. Gallagher, P. Gardner and P. L. Swan, 2007, To herd or not to herd: Do mimicking traders ignore their private information?, Working paper, University of New South Wales.

Fong, K., D. R. Gallagher and A. D. Lee, 2008, Benchmarking benchmarks: Measuring characteristic selectivity using portfolio holdings data, Accounting and Finance, Forthcoming.

Foster, F. D. and S. Viswanathan, 1996, Strategic trading when agents forecast the forecasts of others, Journal of Finance 51, 1437-1478.

Frank, M. M., J. M. Poterba, D. A. Shackelford and J. B. Shoven, 2004, Copycat funds: Information disclosure regulation and the returns to active management in the mutual fund industry, Journal of Law and Economics 47, 515-541.

Gallagher, D.R. and A. Looi, 2006, Trading behaviour and the performance of daily institutional trades, Accounting and Finance 46, 125-147.

Han, B. and Q. Wang, 2004, Institutional investment constraints and stock prices, Working paper, Ohio State University.

Holden, C.W. and A. Subrahmanyam, 1992, Long-lived private information and imperfect competition, Journal of Finance 47, 247-270.

Kacperczyk, M., C. Sialm and L. Zheng, 2005, On the industry concentration of actively managed equity mutual funds, Journal of Finance 60, 1983-2011. 
Nanda, V., Z. J. Wang and L. Zheng, 2004, Family values and the star phenomenon: Strategies of mutual fund families, Review of Financial Studies 17, 667-698.

Pinnuck, M., 2003, An examination of the performance of the trades and stock holdings of fund managers: Further evidence, Journal of Financial \& Quantitative Analysis 38, 811-828.

Politis, D.N. and J.P. Romano, 1994, The stationary bootstrap, Journal of the American Statistical Association 89, 1303-1313.

Sias, R.W., L.T. Starks and S. Titman, 2006, Changes in institutional ownership and stock returns: assessment and methodology, Journal of Business 79, 2869-2910.

Sullivan, R., A. Timmermann and H. White, 1999, Data-snooping, technical trading rule performance and the bootstrap, Journal of Finance 54, 1647-1691.

Wermers, R., 1999, Mutual fund herding and the impact on stock prices, Journal of Finance 54, 581-622.

Wermers, R., 2000, Mutual fund performance: An empirical decomposition into stock-picking talent, style, transactions costs and expenses, Journal of Finance 55, 1655-1703.

Wermers, R., 2003, Are mutual fund shareholders compensated for active management "bets"?, Working paper, University of Maryland.

Wermers, R., T. Yao and J. Zhao, 2006. The investment value of mutual fund portfolio disclosure, Working paper, University of Maryland.

White, H., 2000, A reality check for data-snooping, Econometrica 68, 1097-1126. 
Table 1

Summary Statistics

Table reports the number of funds in the PAD database from 1997-2001 and common stocks in each style. Panel A reports the number of funds by type and by year. Panel B reports the time-series average of commonly held stocks by style, with the diagonal reporting the average number of different stocks held by a style group.

\begin{tabular}{|c|c|c|c|c|c|c|c|c|}
\hline \multicolumn{9}{|c|}{ Panel A. Fund Count } \\
\hline Year & Total Funds & Top 15 & Boutique & GARP & Growth & S Neutral & Other & Value \\
\hline 1997 & 19 & 10 & 4 & 4 & 4 & 4 & 2 & 5 \\
\hline 1998 & 26 & 13 & 9 & 6 & 4 & 5 & 3 & 8 \\
\hline 1999 & 30 & 14 & 12 & 7 & 4 & 7 & 4 & 8 \\
\hline 2000 & 36 & 14 & 15 & 10 & 4 & 7 & 4 & 11 \\
\hline 2001 & 37 & 14 & 16 & 11 & 4 & 7 & 4 & 11 \\
\hline \multicolumn{9}{|c|}{ Panel B. Commonly Held Stocks of Different Styles } \\
\hline \multirow{2}{*}{\multicolumn{2}{|c|}{$\cos ^{2}$}} & GARP & & Growth & \multicolumn{2}{|c|}{ Other } & Style Neutral & Value \\
\hline & GARP & 151 & & & & & & \\
\hline \multicolumn{2}{|l|}{ Growth } & 64 & & 77 & & & & \\
\hline \multicolumn{2}{|l|}{ Other } & 79 & & 55 & & 0 & & \\
\hline \multicolumn{2}{|c|}{ Style Neutral } & 106 & & 62 & & 2 & 136 & \\
\hline \multicolumn{2}{|l|}{ Value } & 107 & & 59 & & 1 & 96 & 131 \\
\hline
\end{tabular}


Table 2

\section{Descriptive Statistics}

At the end of every month from January 1997 to December 2001, stocks in the S\&P/ASX 300 and held by at least one fund manager are placed in one portfolio. All stocks not held by at least one manager are held in another portfolio. The portfolios are value-weighted and held for one month. Panel A reports annualized average monthly characteristicadjusted and raw returns of stocks held and not held by PAD fund managers as well as for the value-weighted holdings of all PAD funds. Panel B reports the average number of stocks held and value-weighted alpha by fund type. Tstatistics are in parenthesis. $* * *, * * *$ denotes statistical significance at the 1,5 and 10 percent level.

\begin{tabular}{ccc}
\hline Panel A. Held and Not Held Stock Returns & \multicolumn{2}{c}{ Raw } \\
\cline { 2 - 3 } Held & Alpha & $11.72^{* *}$ \\
& 0.12 & $(2.04)$ \\
Not Held & $(1.07)$ & -10.31 \\
& $-12.15^{* * *}$ & $(-1.16)$ \\
Held - Not Held & $(-3.94)$ & $20.75^{* * *}$ \\
& $12.27^{* * *}$ & $(3.45)$ \\
VW PAD Funds & $(3.92)$ & $13.81^{* *}$ \\
& $1.27^{* *}$ & $(2.34)$ \\
\hline
\end{tabular}

Panel B. Stocks Held and Alphas by Style

\begin{tabular}{ccccccc}
\hline & Avg. Fund & Stock & Number to S\&P/ASX \\
Stock Count & Count & $\begin{array}{c}\text { Value of } \\
\text { S\&P/ASX } \\
300(\text { percent })\end{array}$ & Alpha & T \\
percent) & & & \\
All & 48 & 208 & 78.05 & 97.58 & $1.27^{* *}$ & $(2.02)$ \\
Top15 & 64 & 189 & 70.87 & 95.86 & $1.41^{* *}$ & $(1.98)$ \\
Middle & 42 & 122 & 45.78 & 89.84 & -0.11 & $(-0.15)$ \\
Boutique & 41 & 118 & 44.30 & 87.93 & 2.04 & $(1.66)$ \\
GARP & 51 & 151 & 56.62 & 92.15 & 0.48 & $(0.55)$ \\
Growth & 42 & 77 & 29.09 & 81.12 & $1.92^{* *}$ & $(2.12)$ \\
Other & 48 & 90 & 33.90 & 84.68 & 0.83 & $(1.22)$ \\
Style Neutral & 51 & 136 & 51.04 & 88.49 & $2.11^{* * *}$ & $(3.58)$ \\
Value & 45 & 131 & 49.29 & 89.83 & $2.11^{*}$ & $(1.86)$ \\
\hline
\end{tabular}


Table 3

\section{Future Performance of Funds Conditional on Past Performance}

Every month from January 1997 to December 2001, funds with adequate past return series are ranked by their past alpha into three groups - high, mid and low past alpha. The table reports each group's equally-weighted average monthly alpha for $\mathrm{Q}+1$ to $\mathrm{Q}+4$ quarters using different past alpha measure sorts. Panel A reports using past one month alpha, Panel B for past quarter alpha and Panel C for past year alpha. Autocorrelation adjusted t-stats following Chopra, Lakonishok and Ritter (1992) are used to measure statistical significance. ${ }^{* * *}, * *, *$ denotes statistical significance at the 1,5 and 10 percent level respectively.

\begin{tabular}{|c|c|c|c|c|c|}
\hline Pr1mth Alpha & $\mathrm{Q}+1$ & $\mathrm{Q}+2$ & $\mathrm{Q}+3$ & $\mathrm{Q}+4$ & $\mathrm{Q}+1$ to $\mathrm{Q}+4$ \\
\hline High & $0.20 * * *$ & $0.14 * * *$ & $0.16^{* * *}$ & $0.13 * * *$ & $0.16^{* * *}$ \\
\hline Mid & $0.12 * * *$ & $0.13 * * *$ & $0.12 * * *$ & $0.11 * * *$ & $0.12 * * *$ \\
\hline Low & $0.09 * *$ & $0.10^{* *}$ & 0.07 & $0.12 * * *$ & $0.10 * * *$ \\
\hline High - Low & $0.11^{* * *}$ & 0.04 & 0.08 & 0.01 & $0.06 * *$ \\
\hline \multicolumn{6}{|c|}{ Panel B. Past Three Month Alpha Ranking } \\
\hline Pr1qtr Alpha & $\mathrm{Q}+1$ & $\mathrm{Q}+2$ & $\mathrm{Q}+3$ & $\mathrm{Q}+4$ & $\mathrm{Q}+1$ to $\mathrm{Q}+4$ \\
\hline High & $0.20 * * *$ & $0.24 * * *$ & $0.16^{* * *}$ & $0.12 * * *$ & $0.17 * * *$ \\
\hline Mid & $0.12 * * *$ & $0.10^{* * *}$ & $0.10^{* * *}$ & $0.10^{* * *}$ & $0.12 * * *$ \\
\hline Low & $0.08^{* *}$ & 0.07 & $0.08 * *$ & $0.11 * * *$ & $0.09 * * *$ \\
\hline High - Low & $0.12 * * *$ & $0.17 * * *$ & 0.08 & 0.02 & $0.08 * * *$ \\
\hline \multicolumn{6}{|c|}{ Panel C. Past Year Alpha Ranking } \\
\hline Pr1yr Alpha & $\mathrm{Q}+1$ & $\mathrm{Q}+2$ & $\mathrm{Q}+3$ & $\mathrm{Q}+4$ & $\mathrm{Q}+1$ to $\mathrm{Q}+4$ \\
\hline High & $0.22 * * *$ & $0.16^{* * *}$ & 0.08 & 0.06 & $0.11^{* * *}$ \\
\hline Mid & $0.09 * * *$ & $0.09^{* *}$ & $0.10^{* *}$ & $0.08 * * *$ & $0.10 * * *$ \\
\hline Low & 0.05 & 0.06 & $0.08^{*}$ & $0.12 * *$ & $0.10^{* * *}$ \\
\hline High - Low & $0.17 * * *$ & 0.10 & -0.01 & -0.06 & 0.02 \\
\hline
\end{tabular}




\section{Table 4}

\section{Alpha Forecast Portfolios}

Every month from January 1997 to December 2001, stocks with at least two managers holding it are given a percentile ranking based on the average overweight of PAD funds and stock popularity (measured by number of funds holding the stock in that month). A score is created by weighting the average overweight and stock popularity percentile rankings. The top 20 stocks with the highest score are then placed into equal-weighted portfolios. The portfolio is held in the second month following formation (i.e. the first month is skipped) for one month and rebalanced monthly. The table reports the annualized average monthly characteristic-adjusted return (with indexadjustment) for these portfolios. 'Factor ( percent)' weights the importance of average overweight percentile in the score (with the remaining weight being in the stock popularity percentile). T-statistics are in parenthesis. ${ }^{* * *},{ }^{* *}, *$ denote statistical significance at the 1,5 and 10 percent level.

\begin{tabular}{clllllc}
\hline Factor Weighting & Oweight & $\mathrm{T}$ & OweightA & $\mathrm{T}$ & Indextimes & $\mathrm{T}$ \\
\hline 0 (Pop Only) & 2.69 & $(1.65)$ & 2.69 & $(1.65)$ & 2.69 & $(1.65)$ \\
10 & $3.95^{* * *}$ & $(2.73)$ & $3.26^{* *}$ & $(2.09)$ & 1.96 & $(1.27)$ \\
20 & 2.25 & $(1.56)$ & $4.28^{* *}$ & $(2.40)$ & $2.98^{*}$ & $(1.92)$ \\
30 & 2.49 & $(1.50)$ & 2.83 & $(1.52)$ & 2.17 & $(1.06)$ \\
40 & 2.55 & $(1.43)$ & 3.20 & $(1.61)$ & 4.39 & $(1.61)$ \\
50 & 1.88 & $(1.00)$ & 3.72 & $(1.77)$ & 3.32 & $(1.12)$ \\
60 & 3.17 & $(1.53)$ & 3.90 & $(1.72)$ & 4.37 & $(1.38)$ \\
70 & 3.11 & $(1.48)$ & 4.49 & $(1.79)$ & 1.56 & $(0.50)$ \\
80 & 2.98 & $(1.34)$ & 3.94 & $(1.46)$ & 4.00 & $(1.19)$ \\
90 & 3.48 & $(1.43)$ & 4.25 & $(1.65)$ & 1.66 & $(0.47)$ \\
100 (Other Only) & 2.67 & $(1.08)$ & 4.22 & $(1.56)$ & -0.70 & $(-0.19)$ \\
\hline Factor Weighting & IndextimesA & $\mathrm{T}$ & AlphaF & $\mathrm{T}$ & & \\
\hline (Pop Only) & 2.69 & $(1.65)$ & 2.69 & $(1.65)$ & & \\
10 & $2.71^{*}$ & $(1.84)$ & $2.53^{*}$ & $(1.86)$ & & \\
20 & $4.10^{* *}$ & $(2.50)$ & $2.83^{* *}$ & $(2.02)$ & & \\
30 & 2.29 & $(1.00)$ & $3.14^{* *}$ & $(2.11)$ & & \\
40 & 3.96 & $(1.37)$ & $4.34^{* *}$ & $(2.41)$ & & \\
50 & $5.62^{* *}$ & $(2.10)$ & $5.21^{* *}$ & $(2.24)$ & & \\
60 & $6.07^{* *}$ & $(2.03)$ & $6.38^{* *}$ & $(2.49)$ & & \\
70 & 2.10 & $(0.62)$ & 4.89 & $(1.65)$ & & \\
80 & 0.35 & $(0.10)$ & 5.93 & $(1.78)$ & & \\
90 & -2.34 & $(-0.66)$ & 2.87 & $(0.68)$ & & \\
\hline 00 (Other Only) & -3.59 & $(-0.99)$ & 2.15 & $(0.48)$ & & \\
\hline
\end{tabular}




\section{Table 5}

\section{Best Strategies Controlling for Data-snooping}

Every month from January 1997 to December 2001, stocks with at least two managers holding it are given a percentile ranking based on average overweight (Oweight), median overweight (OweightA), average index times (Indextimes), median index times (IndextimesA), alpha forecast (AlphaF) or stock popularity (Pop). A score is created by weighting two of the measures. For example a score is the sum of 30 percent of the Indextimes percentile plus 70 percent of the Pop percentile for a stock. We use weighting increments of 5 percent (e.g. 5 percent/95 percent, 10 percent $/ 90$ percent, ... etc.). The top $10,15,20,25$ or 30 stocks with the highest scores are then placed into equal weight $(\mathrm{EW})$, popularity weight $(\mathrm{PW})$ or value weight $(\mathrm{VW})$ portfolios. The portfolio is held in the second month following formation (i.e. the first month is skipped) for one month and rebalanced monthly. This results in a universe of 2655 portfolio strategies. The table presents annualized average alpha and information ratios of the top five strategies with conventional and White's P values. Nstocks is the number stocks held for the strategy, 'Cap Rank' is the equally weighted average quintile by market capitalization $(1=$ smallest quintile, 5 largest $)$ of stocks in the portfolio. Panel A reports the top five strategies by highest IR and Panel B by highest alpha for the entire universe of strategies. Panel C reports the top five strategies by highest IR and Panel D by highest alpha for strategies utilizing 20 or more stocks (1626 strategies).

\begin{tabular}{|c|c|c|c|c|c|c|c|c|c|}
\hline Strategy & Nstocks & Weight & $\begin{array}{l}\text { Cap } \\
\text { Rank }\end{array}$ & IR & $\mathrm{P}$ & $\begin{array}{l}\text { White's } \\
\text { P }\end{array}$ & Alpha & $\mathrm{P}$ & $\begin{array}{c}\text { White's } \\
\text { P }\end{array}$ \\
\hline 80 percent AlphaF 20 percent & 25 & VW & 3.74 & 0.92 & 0.01 & 0.00 & 6.99 & 0.05 & 0.75 \\
\hline 70 percent Indextimes 30 & 10 & VW & 2.81 & 0.91 & 0.03 & 0.00 & 10.75 & 0.04 & 0.15 \\
\hline 85 percent AlphaF 15 percent & 10 & VW & 3.70 & 0.91 & 0.02 & 0.00 & 13.70 & 0.03 & 0.01 \\
\hline 55 percent IndextimesA 45 & 15 & VW & 3.48 & 0.86 & 0.00 & 0.00 & 9.52 & 0.00 & 0.30 \\
\hline 60 percent Indextimes $A 40$ & 20 & VW & 3.16 & 0.85 & 0.00 & 0.00 & 8.77 & 0.01 & 0.41 \\
\hline \multicolumn{10}{|c|}{ Panel B. Top 5 Strategies by Alpha for All Strategies } \\
\hline Strategy & Nstocks & Weight & $\begin{array}{l}\text { Cap } \\
\text { Rank }\end{array}$ & IR & $\mathrm{P}$ & $\begin{array}{l}\text { White's } \\
\text { P }\end{array}$ & Alpha & $\mathrm{P}$ & $\begin{array}{c}\text { White's } \\
\text { P }\end{array}$ \\
\hline 85 percent AlphaF 15 percent & 10 & VW & 3.70 & 0.91 & 0.02 & 0.00 & 13.70 & 0.03 & 0.01 \\
\hline 90 percent AlphaF 10 percent & 10 & VW & 3.47 & 0.79 & 0.04 & 0.00 & 12.47 & 0.04 & 0.05 \\
\hline 70 percent Indextimes 30 percent & 10 & VW & 2.81 & 0.91 & 0.03 & 0.00 & 10.75 & 0.04 & 0.15 \\
\hline 50 percent IndextimesA 50 & 10 & VW & 3.63 & 0.75 & 0.02 & 0.01 & 10.63 & 0.01 & 0.16 \\
\hline 90 percent AlphaF 10 percent & 15 & VW & 3.48 & 0.83 & 0.03 & 0.00 & 10.28 & 0.06 & 0.20 \\
\hline
\end{tabular}

Panel C. Top 5 Strategies by IR for 20 Stock Plus Strategies

\begin{tabular}{|c|c|c|c|c|c|c|c|c|c|}
\hline Strategy & Nstocks & Weight & $\begin{array}{l}\text { Cap } \\
\text { Rank }\end{array}$ & IR & $\mathrm{P}$ & $\begin{array}{c}\text { White's } \\
\text { P }\end{array}$ & Alpha & $\mathrm{P}$ & $\begin{array}{c}\text { White's } \\
\text { P }\end{array}$ \\
\hline 80 percent AlphaF 20 percent & 25 & VW & 3.74 & 0.92 & 0.01 & 0.00 & 6.99 & 0.05 & 0.29 \\
\hline 60 percent IndextimesA 40 & 20 & VW & 3.16 & 0.85 & 0.00 & 0.00 & 8.77 & 0.01 & 0.07 \\
\hline 85 percent AlphaF 15 percent & 20 & VW & 3.60 & 0.85 & 0.01 & 0.00 & 7.73 & 0.07 & 0.17 \\
\hline 55 percent AlphaF 45 percent & 20 & EW & 4.61 & 0.84 & 0.01 & 0.00 & 6.11 & 0.02 & 0.52 \\
\hline 5 percent OweightA 95 percent & 25 & VW & 3.42 & 0.84 & 0.02 & 0.00 & 8.00 & 0.04 & 0.14 \\
\hline \multicolumn{10}{|c|}{ Panel D. Top 5 Strategies by Alpha for 20 Stock Plus Strategies } \\
\hline Strategy & Nstocks & Weight & $\begin{array}{l}\text { Cap } \\
\text { Rank }\end{array}$ & IR & $\mathrm{P}$ & $\begin{array}{c}\text { White's } \\
\text { P }\end{array}$ & Alpha & $\mathrm{P}$ & $\begin{array}{c}\text { White's } \\
\text { P }\end{array}$ \\
\hline 60 percent IndextimesA 40 & 20 & VW & 3.16 & 0.85 & 0.00 & 0.00 & 8.77 & 0.01 & 0.07 \\
\hline 90 percent AlphaF 10 percent & 20 & VW & 3.49 & 0.80 & 0.02 & 0.00 & 8.65 & 0.04 & 0.08 \\
\hline 90 percent AlphaF 10 percent & 25 & VW & 3.29 & 0.68 & 0.05 & 0.02 & 8.08 & 0.05 & 0.12 \\
\hline 80 percent Indextimes 20 percent & 25 & VW & 2.45 & 0.73 & 0.03 & 0.01 & 8.08 & 0.03 & 0.12 \\
\hline 80 percent Indextimes $A 20$ & 20 & VW & 2.41 & 0.71 & 0.07 & 0.01 & 8.07 & 0.06 & 0.12 \\
\hline
\end{tabular}




\section{Table 6 \\ Sub Period Performance of Alpha Forecast Portfolios for 1 to 6 months ( percent per month)}

Table reports the performance of the White's Reality Check Test significant 10 stock and 20 stock strategies from Table 5 from $\mathrm{T}+1$ to $\mathrm{T}+6$ months using alphas and information ratios. We report measures for the first half of the sample period from January 1997 to June 1999, for the latter half from July 1999 to December 2001 and for the full sample period. $* * *, * * *$ denote statistical significance at the 1,5 and 10 percent level.

\begin{tabular}{|c|c|c|c|c|c|c|c|}
\hline \multicolumn{8}{|c|}{85 percent AlphaF 15 percent Pop 10 Stocks Value-Weighted } \\
\hline Period & Measure & $\mathrm{T}+1$ & $\mathrm{~T}+2$ & $\mathrm{~T}+3$ & $\mathrm{~T}+4$ & $\mathrm{~T}+5$ & $\mathrm{~T}+6$ \\
\hline \multirow{2}{*}{ Jan. 1997 - June 1999} & Alpha & 0.56 & 0.72 & -0.07 & 0.43 & -0.06 & -0.03 \\
\hline & IR & 0.50 & $1.02 *$ & 0.03 & 0.16 & -0.10 & 0.22 \\
\hline \multirow[t]{2}{*}{ July 1999 - Dec. 2001} & Alpha & $1.73 * *$ & 0.97 & 0.38 & 0.00 & 0.60 & 0.82 \\
\hline & IR & $1.33 * *$ & 0.83 & 0.34 & -0.09 & 0.07 & 0.68 \\
\hline \multirow[t]{2}{*}{ Jan. 1997 - Dec. 2001} & Alpha & $1.14^{* *}$ & $0.84^{* *}$ & 0.16 & 0.22 & 0.27 & 0.40 \\
\hline & IR & $0.91 * *$ & $0.93^{* *}$ & 0.19 & 0.03 & -0.01 & 0.45 \\
\hline \multicolumn{8}{|c|}{90 percent AlphaF 10 percent Pop 10 Stocks Value-Weighted } \\
\hline \multirow{3}{*}{$\begin{array}{c}\text { Period } \\
\text { Jan. } 1997 \text { - June } 1999\end{array}$} & Measure & $\mathrm{T}+1$ & $\mathrm{~T}+2$ & $\mathrm{~T}+3$ & $\mathrm{~T}+4$ & $\mathrm{~T}+5$ & $\mathrm{~T}+6$ \\
\hline & Alpha & 0.75 & 0.57 & 0.30 & 0.52 & 0.41 & 0.04 \\
\hline & IR & 0.64 & 0.85 & 0.24 & 0.26 & 0.28 & 0.19 \\
\hline \multirow[t]{2}{*}{ July $1999-$ Dec. 2001} & Alpha & 1.34 & 1.01 & -0.16 & -0.11 & 0.96 & 0.78 \\
\hline & IR & 0.94 & 0.79 & -0.05 & -0.23 & 0.42 & 0.83 \\
\hline \multirow[t]{2}{*}{ Jan. 1997 - Dec. 2001} & Alpha & $1.05^{* *}$ & $0.79^{*}$ & 0.07 & 0.20 & $0.69^{*}$ & 0.41 \\
\hline & IR & $0.79 * *$ & $0.82 * *$ & 0.09 & 0.01 & 0.35 & 0.51 \\
\hline \multicolumn{8}{|c|}{60 percent Indextimes $A 40$ percent Pop 20 Stocks Value-Weighted } \\
\hline \multirow{3}{*}{$\begin{array}{c}\text { Period } \\
\text { Jan. } 1997 \text { - June } 1999\end{array}$} & Measure & $\mathrm{T}+1$ & $\mathrm{~T}+2$ & $\mathrm{~T}+3$ & $\mathrm{~T}+4$ & $\mathrm{~T}+5$ & $\mathrm{~T}+6$ \\
\hline & Alpha & 0.41 & 0.22 & 0.03 & 0.42 & 0.09 & -0.29 \\
\hline & IR & 0.53 & 0.11 & 0.03 & 0.55 & 0.08 & -0.45 \\
\hline \multirow[t]{2}{*}{ July 1999 - Dec. 2001} & Alpha & $1.09 * *$ & 0.47 & 0.81 & $1.25^{* *}$ & $1.17 * *$ & 0.81 \\
\hline & IR & $1.22 * * *$ & 0.48 & 0.77 & $1.23 * *$ & $1.17 * *$ & 0.72 \\
\hline \multirow[t]{2}{*}{ Jan. 1997 - Dec. 2001} & Alpha & $0.75^{* * *}$ & 0.34 & 0.42 & $0.84 * * *$ & $0.63^{*}$ & 0.26 \\
\hline & IR & $0.87 * * *$ & 0.29 & 0.40 & $0.89^{* * *}$ & 0.62 & 0.13 \\
\hline \multicolumn{8}{|c|}{90 percent AlphaF 10 percent Pop 20 Stocks Value-Weighted } \\
\hline \multirow{3}{*}{$\begin{array}{c}\text { Period } \\
\text { Jan. } 1997 \text { - June } 1999\end{array}$} & Measure & $\mathrm{T}+1$ & $\mathrm{~T}+2$ & $\mathrm{~T}+3$ & $\mathrm{~T}+4$ & $\mathrm{~T}+5$ & $\mathrm{~T}+6$ \\
\hline & Alpha & 0.54 & 0.36 & 0.07 & 0.37 & 0.04 & -0.33 \\
\hline & IR & $0.80^{*}$ & 0.59 & -0.01 & 0.39 & 0.18 & -0.25 \\
\hline \multirow[t]{2}{*}{ July 1999 - Dec. 2001} & Alpha & 0.91 & 0.16 & 0.59 & 0.62 & 0.33 & 0.59 \\
\hline & IR & 0.79 & 0.13 & 0.46 & 0.48 & 0.07 & 0.53 \\
\hline \multirow[t]{2}{*}{ Jan. 1997 - Dec. 2001} & Alpha & $0.72 * *$ & 0.26 & 0.33 & 0.49 & 0.19 & 0.13 \\
\hline & IR & $0.80 * *$ & 0.36 & 0.22 & 0.43 & 0.12 & 0.14 \\
\hline
\end{tabular}




\section{Table 7}

\section{Cumulative Wealth Algorithm}

At the end of every month from 1997 to 2001, we rank each strategy detailed in Table 5 by its past to date (cumulative wealth $(\mathrm{CW})$ ), month (Pr1mth), quarter (Pr1qtr) or year (Prlyr) alpha (or information ratio). Stocks are chosen to form a portfolio according to the rules of the best performing past strategy and the portfolio is held in the second month after portfolio formation. The table reports the annualized average monthly alpha and IR (information ratio) based on using the best past $\mathrm{CW}$, month, quarter or year performing strategy. Panel A reports results considering the entire universe of strategies and Panel B for only strategies holding 20 stocks and above. T-statistics are in parenthesis. $* * *, * * *$ denote statistical significance at the 1,5 and 10 percent level.

\begin{tabular}{ccccc}
\hline Panel A. All Strategies & & & & \\
\hline Ranking Measure & Alpha & $\mathrm{T}$ & $\mathrm{IR}$ & $\mathrm{T}$ \\
CW Alpha & 5.41 & $(0.99)$ & 0.14 & $(0.37)$ \\
Pr1mth Alpha & 0.80 & $(0.18)$ & -0.04 & $(-0.10)$ \\
Pr1qtr Alpha & 4.49 & $(0.81)$ & $0.72^{* *}$ & $(2.40)$ \\
Pr1yr Alpha & -1.05 & $(-0.22)$ & 0.16 & $(0.40)$ \\
CW IR & 2.21 & $(0.57)$ & 0.05 & $(0.17)$ \\
Prlmth IR & -0.49 & $(-0.12)$ & 0.14 & $(0.45)$ \\
Prlqtr IR & 4.23 & $(0.99)$ & 0.45 & $(1.42)$ \\
Pr1yr IR & -1.50 & $(-0.32)$ & 0.48 & $(1.23)$ \\
\hline Panel B. 20 Stock Plus Strategies & & & $\mathrm{T}$ \\
Ranking Measure & Alpha & $\mathrm{T}$ & $\mathrm{IR}$ & $(0.07)$ \\
CW Alpha & -1.95 & $(-0.49)$ & 0.03 & $(2.61)$ \\
Pr1mth Alpha & $6.88^{* *}$ & $(2.01)$ & $0.82^{* * *}$ & $(1.71)$ \\
Pr1qtr Alpha & $8.61^{* *}$ & $(2.38)$ & $0.61^{*}$ & $(2.14)$ \\
Pr1yr Alpha & 3.64 & $(0.76)$ & $0.82^{* *}$ & $(1.27)$ \\
CW IR & 4.03 & $(1.20)$ & 0.41 & $(2.25)$ \\
Prlmth IR & $6.99^{* * *}$ & $(2.84)$ & $0.61^{* *}$ & $(1.23)$ \\
Pr1qtr IR & 2.82 & $(0.85)$ & 0.38 & $(1.19)$ \\
Pr1yr IR & 5.20 & $(1.25)$ & 0.46 &
\end{tabular}



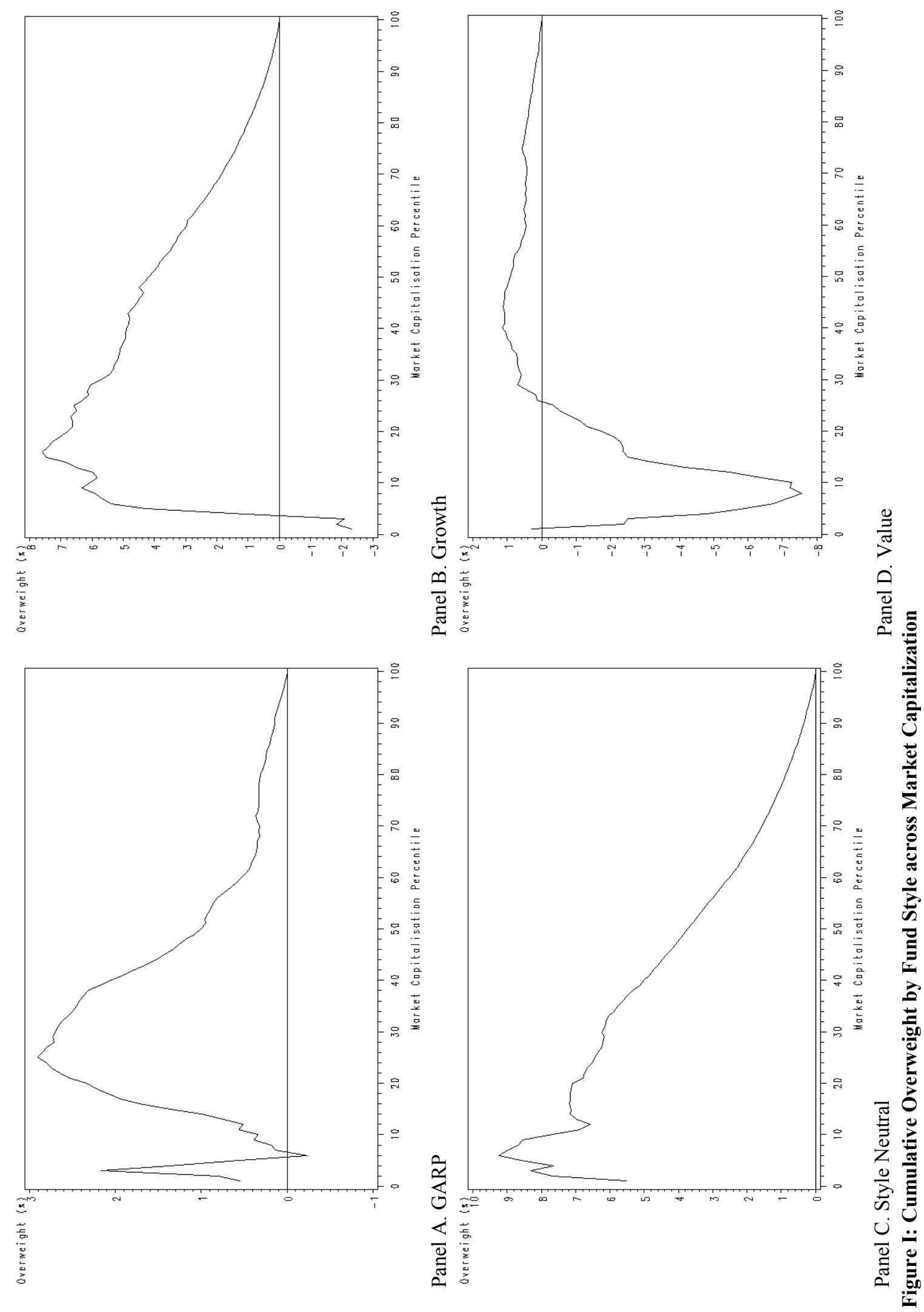